\title{
LOS ERRORES DE LA HISTORIA
}

\section{ERRORS IN HISTORY}

\section{AUTOR}

\section{Pedro Brufao García}

Articulista en varias revistas y publicaciones científicas y de divulgación (España) pedrobrufalo@hotmail.com

\section{RESUMEN}

En una guerra, lo más importante es conocer y dominar los puntos flojos de cada bando. En el bando opuesto para saber dónde y cómo atacar y, en el propio bando para poder evitar y corregir los errores. A lo largo de la historia y durante guerras se han cometido errores que han podido ser clave para la derrota.

\section{PALABRAS CLAVE}

Historia - Guerra - Técnicas - Errores

\section{ABSTRACT}

In a war, the most important thing is to know and dominate the weak points of each side. On the other side to know where and how to attack and, in one's own side to avoid and correct mistakes. Throughout history and during wars have made mistakes that have been key to the defeat. 


\section{KEY WORDS}

History - War - Techniques - Errors

\section{ÍNDICE}

1. El consejo de guerra al Almirante D. Patricio Montojo

2. Los héroes de Cavite: La Escuadra de Filipinas en el año 1898, mandada por el almirante Patricio Montojo.

3. Primero de mayo de 1898

4. Filipinas: una derrota anunciada desde 1884

\section{El Consejo de guerra al Almirante D. Patricio Montojo.}

La vida de los supervivientes del Combate de Cavite quedó marcada para siempre por la amargura y la tristeza, porque se había puesto en duda su honor y buen hacer.

Desde la guerra de 1796 contra Inglaterra en sus intentos de tomar las Filipinas, el Almirante Álava redactó un informe en el que decía: No siendo Cavite susceptible de hacerse intomable, no solo no puede servir de refugio sino que no es posible que haya escuadra en Filipinas mientras Cavite sea el arsenal.

La Base de Cavite tuvo su origen en una cabeza de playa para realizar una "invasión propia" y defenderse de los ataques de tierra, ya que en un principio fue una urbe 
que posteriormente se unió a tierra con una carretera.

El arsenal tiene un puerto que es una verdadera ratonera, que no puede ser defendido por el fuerte y destrozado por la fuerza naval bloqueante.

Hubo un magnífico proyecto para construir y financiar el Shbig, el mejor y más seguro puerto que se podía dotar a Manila, a la que se unió por ferrocarril, pero esta acertada obra diseñada por el Gobernador del Archipiélago en 1880, el preclaro Almirante Antequera, quedó olvidada cuando fue relevado por Primo de Rivera, Marqués de Estella.

Le llegó hasta la consignación de dos millones ochocientos mil pesos según consta en el Acta del Senado de 11 de junio de 1898.

Nuestro bien estimado Capitán de Navío Concas, que fue el defensor del Almirante Montojo en el consejo de guerra por la injusta derrota de Cavite, dijo:

"Casi un siglo había pasado desde que se pudo, cuarenta y siete años desde que se trató oficialmente y diecisiete desde que estuvo el dinero preparado para hacerlo" y hasta su pérdida frente al oportunista americano fue la única colonia del mundo que carecía de puerto militar. $Y$ así pasó que le ofrecimos unos blancos gratuitos para los ejercicios de tiro real de la flota del Comodoro Dewey".

A los pocos años del dominio norteamericano en Subig Bay nacía la espléndida base naval que aún mantiene como punto de apoyo principal a la flota del Pacífico.

Desde enero de 1898 el agregado naval de España en Washington, alertaba que si llegaba a declararse la guerra, el primer objetivo que se atacaría iban a ser las islas Filipinas, cosa que así sucedió. Ampliaba la información, entonces confidencial, la lista de todos los buques norteamericanos apostados en el Pacífico. Un mes después de la voladura del Maine y a cinco semanas de la declaración de guerra con los 
Estados Unidos de América, se intentó reforzar la bahía de Subig con cuatro cañones anticuados muy inferiores a los que montaban los buques enemigos.

Y además los mandos del Ejército de Tierra y de la Armada entraron en agrias discusiones sobre el modo de la defensa, de forma que no se logró tener a tiempo instalados los viejos cañones cuando llegó la hora del combate. El hormigón hidráulico aún no se había consolidado para resistir el proceso de las piezas de artillería.

El día 21 de abril de 1898 se reunió la Junta de Autoridades del Archipiélago para disponer su defensa. Allí se asignó al Almirante Montojo la misión de bloquear la "bocachica" de la bahía de Subig, con buques hundidos ex- profeso y con torpedos minas la "boca grande".

No había casi nada de esto en Manila y hasta buscaron a un boticario que les fabricara fulminato de mercurio, pero no lo consiguieron. Del proyecto inicial de fondear 167 minas sólo se pudieron fondear "cinco". A la vista de tanta precariedad, Montojo reiteró sus necesidades para la defensa al Ministerio de Marina, tanto insistió que al final le mandaron un mensaje cifrado diciendo: "siento no poder mandar recursos".

Hubo promesas y envíos de otro tipo que no llegaron, unos quedaron bloqueados en el Canal de Suez (70 minas) y otros no llegaron a salir de la Base Naval de Cartagena, los cañones de la "Numancia" y de la "Victoria".

Mientras tanto en Madrid, se querían resolver los problemas, como si fuesen asuntos de caridad parroquial haciendo funciones en el Teatro Real para el "fomento de la Marina". Y así llegó la hora de hacerse a la mar para salir al encuentro de los yanquis, así que el 25 de abril, D. Patricio Montojo se hace a la mar y comunica "salgo esta noche con escuadra para Subig. Mis subordinados y yo procuraremos corresponder a las aspiraciones de la Patria". 
Y luego sucedió lo que tenía que suceder por la imprevisión en las decisiones del más alto nivel nacional y además se unieron los celos del Capitán General del Ejército de Tierra, con la autoridad de Marina.

El general Angustín impuso a Montojo que no saliese de la bahía de Manila, con lo que la escuadra quedaba encerrada, como sucedió en Santiago de Cuba y a tiro más que cómodo de los acorazados americanos.

\section{Los héroes de Cavite: La Escuadra de Filipinas en el año 1898, mandada por el almirante Patricio Montojo.}

Si consultamos al Estado General de la Armada del año 1895 realizado en la imprenta de Infantería de Marina de Madrid, aún en la sencillez de las publicaciones oficiales, se pueden percibir los últimos aromas del imperio ultramarino.

La contraseña para los buques de la provincia marítima de las islas Filipinas determinada por esta publicación era una corneta (bandera en forma de corneta), blanca y roja por mitad horizontal, lo blanco en la parte superior. Tendrá cinco paños de ancho y poco más de tres metros de largo total. Las puntas de las cornetas tendrán de largo la mitad de éstas. La largarán en el tope mayor, al mismo tiempo que arbolen en el pico el pabellón nacional, para distinguirse unos de otros en el mar a la vista de los puertos.

En este mismo volumen aparece Patricio Montojo y Pasarán, como capitán de navío de primera clase, Comandante General de Puerto Rico y puesta una anotación a lápiz, "Director de Personal" es decir un cambio de destino entre un año y otro.

Las condiciones eran las siguientes:

- Caballero con cruz y placa de la Real y Militar orden de San Hermenegildo.

- Comendador de número de la Real orden americana de Isabel la Católica. 
- Caballero de la Legión de Honor de Francia.

- Caballero de segunda clase de la Orden del Mérito Naval con distintivo blanco.

- Medalla de El Callao.

- Medalla de Cuba.

- Benemérito de la Patria.

Había nacido el 7 de septiembre de 1839 en el Ferrol (La Coruña) por lo tanto tenía 56 años, llevaba cuatro años en el empleo de Capitán de Navío y 46 de servicios a España.

Le quedaban cuatro años para verse sometido a un duro Consejo de Guerra que ordenó su prisión y la separación del servicio (Marzo de 1899), todo esto como consecuencia del combate naval de Cavite en primero de mayo de 1898 en que la escuadra española bajo su mando fue destruida por la muy superior de los Estados Unidos de Norteamérica.

D. Patricio Montojo era un oficial de la Armada, buen marino, con muchas campañas sobre sus hombros desarrolladas en los mares del Pacífico (Mindanao, China y Conchinchina), participó en la batalla de El Callao a las órdenes de Méndez Núñez (más vale honra sin barcos...)

En Cuba, mandó los buques del aportadero naval de La Habana, pasó brevemente por el Ministerio de Marina y ascendido a Contraalmirante vuelve a Filipinas como Comandante General de las Fuerzas Navales.

Cuando el desgraciado combate, estaban allí como oficiales de la Armada sus hijos Eugenio y Patricio.

El Almirante Montojo era un ilustrado, valiente y sencillo oficial naval que hacía compatible su obligación con la afición a las letras, escribiendo la novela León Aldao, (un ensayo crítico acerca de las primeras tierras descubiertas por Colón, publicado 
por la Junta del Cuarto Centenario del descubrimiento de América), editó un manual náutico enciclopédico, en el que trabajó muchos años. Tradujo la novela inglesa Los dos almirantes de F. Cooper, y la obra del padre Secchi, La Física terrestre.

Colaboró en: Diario de Manila, Diario de Cádiz, Revista General de Marina y otros periódicos. Murió en Madrid el 30 de septiembre de 1917 con ochenta y ocho años.

Desarrolló toda su carrera bajo el factor común de las penurias administrativas oficiales y las particulares de su familia, como la de todas las familias de los marinos de su época.

\section{Primero de mayo de 1898}

Estas penurias y el navegar tocando muchos puentes de diferentes culturas propician la reflexión y el estudio con una serie de oportunidades para conocer a personalidades de las ciencias y de las letras que no tienen los que permanecen asentados en una sola tierra.

Por fuerza se ha tenido que incorporar a las nuevas tecnologías, hemos pasado de la vela al buque de máquina de vapor con hélice, del casco de madera al de acero y de la incomunicación entre continentes al telégrafo por cable submarino y el establecimiento de bases con depósitos de carbón, agua y diques de reparación rápida. La velocidad de la mar pasa de 6 nudos a 25 y el tonelaje se duplica o triplica lo que hace de las rutas marítimas las reinas de la economía mundial.

En España, el presidente Cánovas del Castillo publicó su folleto de "Cómo he venido yo a ser doctrinalmente proteccionista".

El decreto del 21 de diciembre de 1891 aprobó nuevos aranceles que Gual Villalbí califica de "proteccionismo sano". La pérdida de Cuba y Filipinas obligó al gobierno a acentuar todavía más el proteccionismo (arancel en 1906). 
Leopoldo II quiso comprar Filipinas y Canarias, por que las colonias dan prosperidad (Bélgica).

El pasado "prestigioso" pesa de tal forma sobre el pueblo español que lo inmoviliza para llevar a cabo acciones rentables en sus lejanos dominios de singular riqueza.

Mientras España abandona la buena administración de Cuba, Puerto Rico y Filipinas que forzosamente exigen una buena marina civil y militar, se dedica con ahinco a tomar posiciones políticas en África. Que casi lo toca con la mano y el Ejército de Tierra tiene sus inmediatas aspiraciones.

Ha comenzado la pérdida del gran imperio ultramarino para "cambiarlo" por zonas de soberanía en África.

En 1884 se crea la "Sociedad de africanistas y colonialistas", quizás con la segunda intención de que no se instalase en nuestra frontera sur ninguna potencia europea, sobre todo los franceses.

Comenzaron las negociaciones con jefes musulmanes de las tribus confederadas entre Cabo Bojador y Cabo Blanco. Para la rentabilización de esta zona se funda la "Compañía mercantil hispano-africana" y se empieza a construir la ciudad de Villacisneros. Tras algunos avances y atrasos con sus correspondientes ataques consolidamos una extensión de 700.000 kilómetros cuadrados a los que se opone Francia y lo consigue por los tratados de 1900 y 1912 disminuyéndolos en un tercio, precisamente de las zonas más ricas del interior, pero Madrid se conforma por consolidar la frontera africana de las I slas Canarias.

En esta época el pueblo Chino se está expansionando allí donde puede encontrar alguna mejora a su situación y Filipinas no es una excepción.

Inglaterra vigila todo el comercio de los mares de la India y donde Sandokan controla el tránsito entre Filipinas y la Insulindia Neerlandesa. 
La mayoría de las potencias, con colonias en Asia, respetaban la estructura social indígena, creaban sus ciudades "europeas" y explotaban sus riquezas, en cambio España, pretendió asimilar las poblaciones nativas y mediante un clero activo en la evangelización superficial de los tagalos, aunque sin duda alguna la creación de universidades en esos territorios es obra de españoles.

Los frailes defienden a los indígenas de los caciques y además consiguen de Madrid la orden de ocupar Mindanao y Joló, dominadas por los moros (musulmanes) enemigos de los indios filipinos, sobre todo por que los "moros" nos habían tomado Borneo y las Célebes.

Pero lo más importante, el comercio, se nos va escapando de las manos y desde 1811 ningún galeón zarpa para Nueva España (Acapulco).

\section{Filipinas: una derrota anunciada desde 1884}

En todo lo referente a la Armada Española del siglo XIX hay un testigo de excepción, el oficial de Marina D. Víctor Concas y Palau gran cronista de esta historia y actor principal de la misma, su buen hacer histórico fue reconocido nombrándole de la Real Academia de la Historia.

En el año 1884 escribe y publica en la Revista General de Marina, uno de sus artículos titulado "Proyecto de fuerzas navales", del que se editó un opúsculo en la imprenta de Fontanet, de Madrid, situada en la calle Libertad, número 29.

En esa época denuncia que se construían nuevos buques de guerra, no en función de las necesidades de España, sino atendiendo al dinero asignado y lo que se podía construir con el mismo, que eran buques que no servían para la guerra, pero que tampoco ahorran una cantidad de hombres, con sus sueldos que al fin y al cabo no servían para nada, pero así se hacía y así se obedecía. 
En el orden de los acuerdos internacionales, España no quiso firmar el Tratado de París, que ponía fin a la acción de los buques corsarios, por haber pasado a la historia el tiempo de los negreros.

Además, la acción de corso no debe llevarse a cabo mientras una nación tenga sus más ricas ciudades en la costa, sólo defendibles desde el mar, donde el enemigo se puede cobrar con creces.

El "corso", para entendernos, es la guerra de guerrillas; pero en la mar, siempre ventajosa en cuanto que el enemigo no puede dañar las vidas y las riquezas de las costas soberanas.

Concas denuncia con todo acierto que es un error mantener centenares de pequeños buques, años enteros en la mar bloqueando las costas, mientras la Marina abogaba por el único remedio, una escuadra eficaz fondeada tranquilamente en Cartagena.

Si se cae en el error de que el Ejército de Tierra servía para mantener el orden interior, la Marina de 1890 no servía para nada, puesto que no había ningún riesgo interior en Canarias o Baleares.

Durante estos años se dió más importancia al artillado de algunos puntos de la costa, que a una escuadra que puede defender cualquier costa y todos sus puertos.

Después de definir las escuadras de base en la Península, describe la escuadra de combate, necesaria para la lucha transatlántica, y que estará divida en dos grupos de combate, tres cruceros, cuatro torpederos descubridoras, un transporte de material y un buque portador de torpederos de segunda clase.

Los grupos de combate así formados pueden defender Cuba y Filipinas, poniendo gran atención en sus tripulaciones; ya que buques sin instrucción son buques perdidos. 
En Inglaterra, de gran conciencia marítima, se premia a las dotaciones cuando regresan de una campaña navegando en Ultramar con un año de licencia con sueldo entero y derecho a embarcar tres años en buques de la reserva con base en el puerto de residencia familiar.

Así que tiene un año para atender a su patrimonio y cuatro para tutelar la familia.

Hace una denuncia a lo poco económico que es contratar el transporte de tropas. Con la empresa López, que crecía "fabulosamente" en las campañas de Cuba, México y Santo Domingo (anterior a 1884), así como las compañías de Olano y Campo en Oriente.

En estos años, la Compañía Transatlántica cobra por cada pipa de vino llevada a Cuba diez dólares, precios extraordinarios, así como la Compañía Campos sostiene unos fletes taller que nos compensan más llevar nuestros azúcares y cafés a Liverpool y volvero a España, que traerlo directamente por una compañía que sostienen exclusivamente los contribuyentes españoles. Esto hacía que los intereses comerciales de Filipinas y Cuba se uniesen más a Liverpool que a España.

Las poderosas razones comerciales han hecho que cada año se adelantase en diez la separación de los territorios españoles de Ultramar.

Reseña también el despilfarro del estado en el transporte de tropas en las Compañías antes citadas, especialmente la de López. Las ganancias fueron grandiosas por el efecto multiplicador de los hombres y los días de mar.

El ejemplo más claro es lo que cuesta un pasaje de España a Filipinas en un camarote de primera por el que se cobró doscientos cincuenta y siete dólares, siendo el gasto de doscientos dólares, el beneficio es ínfimo. Pero la empresa Olano recibía cuatrocientos dieciséis dólares por pasaje, poniendo cuatro hombres en cada camarote, lo cual era un abuso consentido por el Ministerio de Ultramar, a pesar de las denuncias. 
En el caso de las tropas, el Estado paga noventa dólares, por lo que un relevo cuesta ciento ochenta dólares, pero van, en las bodegas de carga y como pueden en la cubierta, llegando a La Habana con la "sentencia de muerte en la cara".

Mientras otros países llevan a sus tropas en cómodos y seguros "transportes de guerra", cada uno con su litera y a cubierto de las inclemencias de mar y viento, con frio y con calor, con sol o con lluvia. Caso de excepción fueron las fragatas desartilladas que llevaron tropas a Cuba, del orden de 1800 soldados cada una y que llevaron a los mismos de tal forma cómodos que no parecían compañeros de los que llevaron los vapores comerciales (antes de 1884).

En los embarques a Filipinas, el armador ganaba 78 dólares por hombre. El relevo oficial es cada cuatro años, pero por bajas y enfermedad resulta un tiempo real de tres años. Entre Cuba, Puerto Rico y Filipinas el Estado gasta medio millón de pesos fuertes, en tiempo de paz.

También sucedía que los buques de guerra al servicio del Ejército, eran empleados en transportes no económicos que derrochaban hombres, sueldos, material y combustible.

En líneas generales, parecía que los ministerios de Ultramar, Ejército y Marina, fuesen de naciones poco amigas, sin hacer planes de economía complementaria entre unos y otros. 